\title{
Crítica à Teoria da Maternidade em Winnicott: é Preciso ser Mulher para cuidar de Crianças?
}

\author{
Jhonatan Jeison de Miranda \\ Alberto Luiz Rodrigues Timo \\ Universidade Federal de Minas Gerais, MG, Brasil. Universidade Federal de Minas Gerais, MG, Brasil. \\ Fábio Roberto Rodrigues Belo \\ Universidade Federal de Minas Gerais, MG, Brasil.
}

\begin{abstract}
Resumo: Ao longo das décadas de convivência com o feminismo, a psicanálise sofreu pertinentes críticas com relação à suposição da figura paterna como eixo central de sua teoria de constituição subjetiva. O maternalismo, por outro lado, destaca-se como a corrente pós-freudiana que toma o cuidado materno como modelo teórico e prático por excelência. No entanto, endossando uma perspectiva feminista, a centralização da maternidade não deixa de apresentar sérios riscos, pois se conecta diretamente a relações de poder e dominação que contribuem para a circunscrição das mulheres ao âmbito doméstico. Donald W. Winnicott, importante psicanalista britânico e expoente do maternalismo, estabelece a quase exclusividade do cuidado de crianças exercido por mulheres. Embora haja um aumento da discussão sobre o tema nos últimos anos, ainda é escasso o questionamento crítico do papel da paternidade em Winnicott. Este trabalho problematiza a ênfase dada à maternidade por Winnicott, de modo a tensionar sua exclusão da paternidade como possibilidade de cuidados de bebês. A partir do método psicanalítico proposto por Jean Laplanche articulado à função normativa dos discursos de gênero, como formulado por Judith Butler, analisamos dois argumentos winnicottianos sobre a maternidade. Foi possível evidenciar a reafirmação da hierarquia dos gêneros no cuidado com bebês realizada através de recursos essencializantes e apontar alternativas teóricas para a compreensão da evitação do rearranjo dos lugares de cuidado. O desamparo gerado na situação de cuidado destacou-se como um dos sustentáculos da exclusão de homens dessa posição.
\end{abstract}

Palavras-chave: Maternidade, Paternidade, Winnicott, Gênero, Psicanálise.

\section{A Critical Approach to Winnicott's Theory of Motherhood: Do you have to be a Woman to take care of Children?}

\begin{abstract}
Through decades of familiarity with feminism, Psychoanalysis suffered important critics about the supposition of the paternal figure as central axis of its subjective constitution theory. Maternalism, by other hand, shows itself as a post-Freudian lead that takes maternal care as a theoretical and practical model par excellence. However, endorsing a feminist perspective, the centralization of maternity also presents serious risks, for it connects directly to power and domination relations that contribute for the circulation of women in the domestic reign. Donald W. Winnicott, important British psychoanalyst and exponent of maternalism, establishes the almost exclusivity of children care wielded by women. Although the discussion about the theme has increased in the last years, the critical questioning about the paternity role in Winnicott is still rare. From the psychoanalytical method proposed by Jean Laplanche articulated to the normative function of gender discourses, as formulated by Judith Butler, we analyze two Winnicottian arguments about maternity. It was possible to highlight the reaffirmation of gender hierarchy in babies care made through essentializing resources. Helplessness originated from the care situation showed to be one of the justifications for excluding men from this position.
\end{abstract}

Keywords: Maternity, Paternity, Winnicott, Gender, Psychoanalysis. 


\title{
Crítica a la Teoría de la Maternidad en Winnicott: ¿hay que ser Mujer para cuidar de Niños?
}

\begin{abstract}
Resumen: A lo largo de las décadas de convivencia con el feminismo, el psicoanálisis ha sufrido críticas relevantes con respecto a la asunción de la figura paterna como eje central de su teoría de la constitución subjetiva. La maternidad, por otro lado, se destaca como la corriente postfreudiana que toma la atención materna como modelo teórico y práctico por excelencia. Sin embargo, al respaldar una perspectiva feminista, la centralización de la maternidad presenta serios riesgos, ya que se conecta directamente con las relaciones de poder y la dominación que contribuyen a la circunscripción de las mujeres en la esfera doméstica. Donald W. Winnicott, un destacado psicoanalista británico y un exponente del maternalismo, establece el cuidado casi exclusivo de los niños por parte de las mujeres. Aunque ha habido una creciente discusión sobre el tema en los últimos años, el cuestionamiento crítico sobre el papel de los padres en Winnicott es aún escaso. Este documento problematiza el énfasis de Winnicott en la maternidad para enfatizar su exclusión de la paternidad como una posibilidad de cuidado infantil. Desde el método psicoanalítico propuesto por Jean Laplanche articulado a la función normativa de los discursos de género, tal como fue formulado por Judith Butler, analizamos dos argumentos winnicotianos sobre la maternidad. Fue posible resaltar la reafirmación de la jerarquía de género en el cuidado de los bebés realizada a través de recursos esenciales y señalar alternativas teóricas para comprender la evitación de la reorganización de los lugares de cuidado. La impotencia generada en la situación asistencial se destacó como uno de los pilares de la exclusión de los hombres de este puesto.
\end{abstract}

Palabras clave: Maternidad, Paternidad, Winnicott, Genero, Psicoanálisis.

O maternalismo se destaca como uma das grandes revisões efetuadas por psicanalistas pós-freudianos (Sayers, 1992; Chodorow, 1989). Esse fenômeno pode ser entendido como a tomada do cuidado materno como modelo teórico e prático por excelência, afastando-se das descrições e análises que concebem o pai como fundamento das subjetividades. É notável como a valorização das mulheres através da maternidade teve papel importante na relação da psicanálise com o feminismo ao longo do século XIX, tendo sido uma postura feminista adotada por autoras psicanalistas como Horney (1991) e mais recentemente Cixous, Irigaray e Kristeva (Stevens, 2005).

As psicanálises de origem inglesa de modo mais proeminente avançaram na direção da maternalização a partir de Melanie Klein e seus sucessores e dissidentes (Sayers, 1992). Donald W. Winnicott é um autor que se insere em tal linhagem e como o próprio autor analisa nos anos finais de sua vida, "já posso ver em meu trabalho o importante papel desempenhado pelo impulso de descobrir e valorizar a boa mãe comum" (Winnicott, 2011, p. 117).
No entanto, endossando uma perspectiva feminista sobre a psicanálise, percebe-se que há grandes riscos no movimento de centralização da maternidade (conferir Doane \& Hodges, 1992). Sobre essa questão, os feminismos variaram de postura ao longo do tempo, partindo das desvantagens e vantagens em direção à desbiologização da maternidade e ao apontamento das relações de poder e dominação que perpassam esse fenômeno (Scavone, 2001). Nessa direção, Riley (1983), por exemplo, evidencia como a Segunda Guerra Mundial mobilizou um grande empenho de instituições e teorias britânicas no sentido de fazer com que as mulheres regressassem para o âmbito doméstico. A maternidade é então utilizada nesse contexto como forma de reorganização social. Não coincidentemente, no mesmo período Winnicott volta sua obra para bem caracterizar a unidade mãe-bebê estabelecendo uma exclusividade do cuidado de crianças por mulheres.

Em função desse exclusivismo, tem-se discutido nos últimos anos o papel da paternidade em Winnicott (Belo, Guimarães \& Fidelis, 2015; Reeves, 2013; 
Rosa, 2014a) ${ }^{1}$. Muitos desses trabalhos realizam uma sistematização dos dispersos trechos em que o autor aponta o papel secundário da paternidade, sendo poucos os que ousam reler criticamente o binarismo de gênero situado por Winnicott no cuidado de crianças. Tendo em vista esse debate, o presente trabalho tem como objetivo problematizar a ênfase dada à maternidade por Donald W. Winnicott através de alguns conceitos de sua teoria de modo a tensionar sua exclusão da paternidade como possibilidade de cuidados de bebês. Optamos por abordar a perspectiva binária maternidade-paternidade, homens-mulheres, analisando os lugares de gênero tradicionalmente fixados como forma de apontar a lógica de dominação que subjaz ao binarismo na teoria winnicottiana.

\section{Método}

A leitura de textos winnicottianos realizada neste trabalho é direcionada pelo pensamento metodológico de Laplanche (1988, 1992). Nessa perspectiva, partimos do pressuposto de que toda formulação teórica em psicanálise se dá em um misto de expressão e defesa do sexual, quer dizer, da alteridade constitutiva dos fenômenos psíquicos e subjetivos. Isso quer dizer que o pensamento psicanalítico, ao se dedicar à elucidação desses fenômenos é perpassado pela dificuldade de apreender a radicalidade da alteridade que os origina e assim faz uso de artifícios teóricos, através dos quais, pode dizer sobre eles e também deles se desviar e se defender.

Grosso modo, a alteridade sexual pode ser aludida do ponto de vista interno, o inconsciente como outro interno que dá base para o psíquico, e externo, o outro social que precede a toda subjetividade. Como veremos, a discussão de Winnicott acerca da maternidade dá peso à alteridade externa - ambiental, em seus termos - e está intimamente articulada com a forma como o autor compreende que os cuidados de adultos são condição para as origens psíquicas dos bebês.

Dessa forma, o caminho a ser percorrido neste trabalho vai no sentido de analisar as afirmações e justificativas empregadas no pensamento de Winnicott para afirmar a centralidade da maternidade na situação de cuidado de crianças. Analisar as estratégias argumentativas de Winnicott busca compreender as defesas que se fazem presentes em seu pensamento e visa alcançar um nível de elaboração além daquele que o autor se permite dizer. A análise de textos winnicottianos não se presta à exposição de uma coerência interna da obra do autor, bem como a utilização de suas elaborações teóricas e práticas pode ser colocada contra o ponto de vista dele mesmo.

Aproximamos neste trabalho o método laplancheano e a perspectiva de Butler (2013) ao revelar e problematizar as estratégias discursivas naturalizantes da teoria winnicottiana sobre o cuidado de bebês como defesas relativas à presença do sexual na dinâmica entre os gêneros. Lima e Belo (2019) fazem percurso semelhante ao que propromos, a partir da mesma metodologia, qual seja questionar identidades veiculadas pela teoria psicanalítica presentes, por exemplo, no que é ser uma mulher ou uma mãe.

Este tipo de metodologia que emprega análise crítica à teoria psicanalítica voltada para a descrição do que é ser mulher tem uma longa história, em especial aquela construída pela crítica feminista à psicanálise. Mitchel (1979) e Chodorow (1989) são exemplos notáveis de emprego desse método: questionamento sistemático da teoria valendo-se de outros aspectos da própria teoria psicanalítica.

Entendemos que o discurso teórico articula a um só tempo os movimentos inconscientes presentes entre a teoria e seu contexto de produção, possibilitando perguntar: o que Winnicott revela sobre gênero ao defender a maternidade como função exclusiva no cuidado de bebês? Como compreender a marginalidade à qual Winnicott relega a paternidade e outros lugares de cuidado ao tensionarmos suas próprias elaborações teóricas?

\section{Discussão}

\section{Mulheres e cuidado}

A obra de Winnicott é enfática no que diz respeito à definição dos lugares de gênero nas tarefas de cuidado e endossa uma visão de família heteronormativa (Belo et al., 2015). O autor não hesita em afirmar que são as mães - e, em última instância, as mulheres que devem se ocupar dos cuidados infantis. Endereça

${ }^{1} \mathrm{O}$ contexto de debate sobre gênero efervescido pelo impacto do feminismo nas ciências humanas não pode ser negligenciado para se compreender a emergência dessas discussões. Já sensível aos problemas de gênero, Winnicott escreve seu pequeno texto “E o pai?", deixando evidente o secundarismo dos pais tanto em seu objeto quanto em sua teoria. As justificativas do autor parecem embasar e serem repetidas pelos winnicottianos que se dedicam ao assunto. 
às mães leitoras/ouvintes vários textos e palestras radiofônicas (Winnicott, 1982a, 1987, 1999) em que lhes fala sobre o sentido do cuidado dos bebês. Ao fazer isso, afirma também que não pretende ensiná-las como devem se sentir e se portar com seus filhos, pois uma mãe "age naturalmente" (Winnicott, 1982a, p. 4). Por ora, a despeito do sentido do "naturalmente", fica evidente que, para Winnicott, é incoerente um homem saber sobre o que é cuidar de filhos:

Para começar, você ficará aliviada, leitora, quando souber que não tenciono explicar o que tem a fazer. Sou homem e, portanto, jamais poderei saber, na verdade, o que se sente ao ver ali embrulhado [sic] uma parcela do meu próprio ser, um pedaço de mim vivendo uma vida independente... Só uma mulher pode sentir isso e, talvez, só uma mulher possa até imaginar essa experiência quando, por infortúnio de uma ou outra espécie lhe falta a prova real e concreta (Winnicott, 1982a, p. 15).

Dessa maneira, Winnicott vê importância em uma diferenciação entre sexos no que diz respeito ao domínio dos saberes sobre cuidados de recém-nascidos e se posiciona a partir disso. No texto citado, "Um homem encara a maternidade" (Winnicott, 1982a), o autor evidencia sua posição de exterioridade em relação ao cuidado infantil em função da demarcação do lugar dos homens e mulheres neste cuidado. Como veremos, Winnicott apresenta uma construção de gênero bem marcada por fatores biológicos, sem problematizar sobre estas construções, que são sociais. A tradução do título para o Brasil ${ }^{2}$ capta bem os problemas de gênero que estão presentes: é preciso alguma coragem para que homens encarem a maternidade ou, em outros termos, as tarefas de cuidado a ela atribuídas. Quais perigos precisam ser encarados?

As tarefas de cuidado com crianças recém-nascidas no estágio da dependência absoluta são caracterizadas pelo holding (Winnicott, 1996). Sobre esse conceito, o autor compreende a atividade ampliada de segurar o bebê, ou seja, todos os cuidados dispensados pelo adulto que, identificado com a criança, adquire sensibilidade acerca das necessidades dela. Trata-se de uma "adaptação sensível" (Winnicott, 1982b, p. 82) ou uma "adaptação viva às necessidades do lactente" (Winnicott, 1982b, p. 52, grifo do autor).
Com esses termos, Winnicott quer dizer que é o ambiente que precisa se adaptar ao bebê, mas não de uma maneira mecânica, como uma máquina poderia fazer (conferir Winnicott, 1996, p. 30). Porém, junto com as máquinas, na lógica binarista dos gêneros, a paternidade também é excluída dessa capacidade de adaptação sensível às necessidades do bebê, como se percebe em seu texto sobre a paternidade (Winnicott, 1982a). Portanto, em que consistiria esse "privilégio" que Winnicott concede às mulheres como sendo mais capazes de fornecer holding aos bebês?

\section{Gravidez e seu papel no estabelecimento da preocupação}

Ao se debruçar sobre o conceito de preocupação materna primária, condição para o holding do recém-nascido, Winnicott nos apresenta um primeiro argumento que procura sustentar o papel exclusivamente materno do cuidado infantil, qual seja, o de que as mães se preparam, salvo nos casos em que estejam "psiquiatricamente doentes" (Winnicott, 1996, p. 30), para sua tarefa nos últimos meses de gravidez e que depois retornam "ao seu estado normal nas semanas e meses que se seguem ao processo de nascimento" (p. 30).

$\mathrm{O}$ autor estabelece a gravidez como fator determinante para o surgimento da capacidade de adaptação às necessidades dos bebês. $O$ saber natural das mulheres sobre os bebês é atribuído ao corpo e às mudanças nele ocorridas pela gestação. Diz o autor que, "no início, essas mudanças são quase fisiológicas, e começam com a sustentação física do bebê no útero... Sem dúvida as mudanças fisiológicas sensibilizam a mulher para as mudanças psicológicas mais sutis que se seguem" (Winnicott, 1982b, pp. 51-52). A dimensão psíquica do cuidado materno, para Winnicott, surge a partir da dimensão fisiológica do corpo. Essa sequência biológico-psíquica coincide com sua descrição sobre o processo ocorrido com o outro componente dessa relação, o bebê, para o qual no estabelecimento da dependência absoluta "a fisiologia e a psicologia ainda não se tornaram separadas" (Winnicott, 1982b, p. 48). É o holding da mãe que possibilita tal separação e constituição da dimensão psíquica na criança. Percebemos, assim, um paralelismo entre o que ocorre com a mãe e o que ocorre com o bebê que permite vislumbrar uma lógica explicativa sobre a situação originária em que o psíquico advém do fisiológico.

${ }^{2}$ O título original é “A man looks at motherhood” (conferir Hjulmand, 1999). 
Fatores psicológicos são também considerados pelo autor no estabelecimento da preocupação materna primária (por exemplo, Winnicott, 1982b, p. 51). No entanto, há uma preponderância da determinação fisiológica que pode ser ou não distorcida por fatores psicológicos e ambientais. Mesmo não concluindo uma determinação fisiológica total implicada no estabelecimento da preocupação materna primária, o papel da dimensão psicológica e ambiental é o de desviar ou não o fator teleológico natural fundamentado na fisiologia. Como o ponto de partida da argumentação winnicottiana sobre o cuidado dos bebês é fisiológico, procuramos compreendê-lo como uma tática defensiva que evita o reconhecimento do sexual alteritário (Laplanche, 1992) e, desse modo, serve como estratégia discursiva para a produção de uma coerência sexo-gênero-desejo (Butler, 2013).

Um contraponto ao predomínio da sequência Fisiologia-Psicologia parece estar contido na seguinte ideia: "Quando uma mulher tem uma forte identificação masculina, é-lhe extremamente difícil atingir esta parte de sua função materna e uma inveja do pênis reprimida deixa pouco espaço para a preocupação materna primária" (Winnicott, 1982c, p. 494). Aqui podemos deduzir uma inversão ou uma grande sobreposição do psicológico (o campo das identificações) sobre o fisiológico. A capacidade de adaptação às necessidades do bebê manifesta-se ou não a depender das identificações do cuidador que acompanham sua participação na situação originária.

Outro ponto que podemos levantar contra o argumento da gravidez refere-se à presença de sacrifícios na situação originária. Nessa direção, Winnicott (1982c) discorre sobre mulheres que não são capazes de manifestar a preocupação materna primária:

Certamente, existem muitas mulheres que são boas mães sob todos os outros aspectos e que são capazes de manter uma vida rica e proveitosa mas que não conseguem atingir esta "doença normal" que as capacitaria a se adaptar delicada e sensivelmente às necessidades iniciais do bebê; ou então a atingem com um filho e não com outro. Estas mulheres não são capazes de se preocupar com seu próprio bebê, a ponto de excluir outros interesses, da maneira que é normal e temporária. Pode-se supor a existência de uma "fuga para a sanidade" em algumas dessas pessoas (Winnicott, 1982c, p. 494).
A concepção de que a preocupação materna primária consiste em um estado doentio ao mesmo tempo em que normal, fruto de uma entrega natural da mulher, coloca uma aparente contradição que se expressa mais claramente entre os termos presentes nas expressões "doença normal" e "fuga para a sanidade”. Colón (2009) desfaz a contradição ao afirmar que é a perspectiva do filho (suas necessidades) que opera como critério, resultando no caráter negativo para o que seria a saída emancipatória da mulher, a saúde. Entendemos que não há vínculo necessário entre doença e maternidade (paternidade ou qualquer outra figura de cuidado), nem entre saúde e "preocupações alternativas", como uma vida profissional etc. Porém, a partir dos termos utilizados pelo autor, evidencia-se um incentivo teórico a um prejuízo dito natural a partir do gênero ou, como resume Colón (2009), à sujeição das mulheres a partir da figura materna.

Note-se que há uma concorrência entre "preocupações alternativas muito grandes" e a preocupação materna primária, eleita como principal. Essas alternativas à dedicação com recém-nascidos, mais do que meras fugas à entrega natural, podem ser entendidas como identificações concorrentes que se articulam ou não com os gêneros e que se contrapõem à maternidade. Chama a atenção aqui o termo preocupação, muito utilizado pelo autor no trecho citado para avaliar a dedicação materna aos cuidados. A capacidade de se preocupar ou de concerné descrita por Winnicott como:

o elo entre os elementos destrutivos do relacionamento instintivo com o objeto, e os outros aspectos positivos de se relacionar... a ansiedade sobre os impulsos do id e as fantasias destes impulsos se tornam toleráveis para o bebê, que pode então experimentar culpa, ou pode retê-la totalmente, na expectativa de uma oportunidade para fazer a reparação dela (Winnicott, 1982c, pp. 77-78).

Desse modo, a capacidade para se preocupar consiste na integração da ambivalência afetiva a partir da sobrevivência do objeto, o que possibilita à criança sentir culpa e confiar que a reparação de sua destrutividade seja possível. Ao entender o termo "preocupação materna primária" a partir da definição da capacidade de se preocupar, percebemos que ela não é um atributo particular de um gênero e diz respeito mais à confiança na reparação das falhas em ser um cuidador suficientemente bom do que a uma sensibilidade exacerbada. 
O caráter doentio dessa adaptação às necessidades da criança destacado por Winnicott pode ser mais explorado. $\mathrm{O}$ autor o descreve da seguinte forma:

Este estado organizado (que, não fosse pela gravidez, seria uma doença) poderia ser comparado a um estado retraído, ou a um estado dissociado ou uma fuga, ou mesmo a uma perturbação a um nível mais profundo, tal como um episódio esquizóide, no qual algum aspecto da personalidade assume temporariamente o controle (Winnicott, 1982c, p. 494).

Parece importante valorizar alguns aspectos presentes nesse estado de cuidado dedicado ao mesmo tempo em que se critica sua marcação generificada. A descrição acima pode ser resumida em três partes: há um grande afastamento das demais atividades que mobilizavam o conjunto daquela personalidade; ocorre uma cisão no interior dessa personalidade; um elemento torna-se dominante. De fato, o cuidado de recém-nascidos frequentemente envolve o investimento maciço e o afastamento dos investimentos concorrentes que fazem parte do cotidiano das famílias. Esse investimento é direcionado pela identificação com o bebê, aspecto da personalidade que assume temporariamente o controle e leva o cuidador a entrar em contato com sua própria passagem pela dependência absoluta. No entanto, mais do que uma habilidade de empatia, afirma que é preciso ser capaz de se deixar adoecer. A doença a ser enfrentada pelo cuidador pode ser entendida como o efeito das falhas ambientais que permearam sua própria experiência de dependência. Seguindo a leitura laplancheana de Winnicott, as falhas ambientais evocadas pela experiência de cuidado se referem aos efeitos da sexualidade adulta na cena originária, os quais geram a cisão que inaugura as tópicas psíquicas, o recalcamento originário. A comparação que o autor faz entre a preocupação materna primária e as perturbações dissociativas presentes em um episódio esquizoide apontam justamente para as fortes defesas que precisam ser empreendidas para a contenção do sexual. Dessa forma, o exercício do holding de bebês efetuado por um adulto com inconsciente e mecanismos defensivos operando traz à tona um esforço psíquico em se colocar no lugar do bebê e vivenciar os aspectos disruptivos, bem como os processos recalcantes que foram utilizados nessa cena. O estado doentio se refere, assim, à revivescência do desamparo de um eu frente aos conteúdos inconscientes evocados pela situação de dependência, ou seja, pelo desamparo do bebê.

$\mathrm{O}$ autor destaca o corpo no estabelecimento da preocupação materna primária, quando lembra que a mulher grávida começa a dirigir sua atenção para si própria, encorajada por seu próprio corpo, transferindo seu interesse também para "o bebê que está crescendo dentro dela” (Winnicott, 1982b, pp. 51-52). Indo muito além das determinações fisiológicas, o autor aponta que as alterações nos corpos das mulheres durante a gravidez auxiliam a articular seu próprio narcisismo com o narcisismo dos bebês a partir do investimento que farão neles.

Lembremos que, para Winnicott (1990), o corpo é uma aquisição psíquica propiciada pelo holding do cuidador. Como as citações winnicottianas acima evidenciam, os corpos são marcados pelos discursos de gênero, de modo que as alterações da gravidez podem propiciar às mulheres o uso de identificações que as facilitaram no estabelecimento do próprio gênero incorporado. Têm assim, à mão, toda uma história marcada por discursos de assujeitamento a partir do gênero feminino que as direcionam para a performatização (Butler, 2006) de corpos que engravidam para cuidar. Tal performatização compõe o processo egoico de manutenção das tópicas psíquicas, tão importante para a revivescência da cena originária com o bebê, como já afirmamos.

\section{Argumento MULHER}

O segundo argumento de Winnicott a ser trabalhado refere-se ao seu conceito de MULHER, grafado desta forma, com todas as letras maiúsculas. Esse conceito opera como um diferenciador binário de gênero que justifica que mulheres possam se dedicar ao cuidado de recém-nascidos e homens não, como explicitaremos mais à frente.

No texto "Este feminismo" (Winnicott, 2011) o autor define MULHER como: "a mãe não-reconhecida dos primeiros estágios de vida de todo homem e de toda mulher" (Winnicott, 2011, p. 193). A princípio, sua marca se faz na vida psíquica de todas as pessoas por se referir aos primórdios da vida. A qualidade de "mãe não reconhecida" aponta para o estágio de dependência absoluta, quer dizer, não foi reconhecida porque não havia um eu do bebê para reconhecê-la. Dessa forma, para bem especificar o conceito: "é necessário dizer que no começo todo mundo era com- 
pletamente dependente de uma mulher e, depois tornou-se relativamente dependente... Isso significa uma adaptação inicial sensível da parte de um ser humano. Esse ser humano é mulher, e geralmente mãe" (Winnicott, 2011, p. 192, grifo do autor).

Notemos que há a pressuposição de que em todo começo de vida psíquica pode-se identificar a presença de uma mulher. Ao mencionar "a adaptação inicial sensível de um ser humano" remete o leitor à preocupação materna primária, ou seja, está falando sobre os cuidados iniciais que são providos à criança. Ao mesmo tempo, baseia-se no fato da gestação e do parto serem próprios de um tipo de corpo, indicando outro princípio que não seria o dos cuidados: "Entretanto, todo homem e toda mulher crescem dentro de um útero, e todos nascem, nem que seja através de uma operação cesariana" (Winnicott, 2011, p. 192). Logo em seguida, corrige-se: "Descobrimos que o problema não é tanto que todas as pessoas estavam lá dentro [do útero] e depois nasceram, mas que no início todas as pessoas foram dependentes de uma mulher" (Winnicott, 2011, p. 192, grifo do autor). Dessa forma, há uma tensão sobre o que seria o critério definidor do conceito de MULHER. Se se trata dos cuidados maternos, pode-se avaliar contextualmente cada história individual ou mesmo supor a existência de grupos onde a subjetivação permita descobrir um HOMEM, uma AVÓ, uma CRECHE ou qualquer outra denominação para aquela figura que permitiu o estabelecimento da dependência. Se o princípio que Winnicott menciona for relativo a um tipo de corpo que pode gerar bebês em seu interior, o conceito é uma generalização naturalizante de uma função materna de cuidado que compreende que haja uma necessidade entre útero e o cuidado de crianças.

Percebemos que ao falar de MULHER, Winnicott (1982a, 2011) enfatiza o fato da dependência e em poucos momentos relaciona-o de alguma maneira a um corpo biológico, como na passagem citada acima. Isso indica que pretende se referir aos cuidados que acompanham a dependência do bebê. Essa possibilidade interpretativa, como já mencionamos, abriria margem para a substituição da figura não reconhecida a partir de quem efetivamente cuidou da criança. Porém, ela é anulada pela saída metafísica que o autor encontra:

Podemos encontrar um novo modo de especificar a diferença entre os sexos. As mulheres o possuem quando se relacionam com a MULHER, através de uma identificação com ela. Para toda mulher, há sempre três mulheres: 1) o bebê menina, 2) a mãe, 3) a mãe da mãe... Não importa se tenha bebês ou não, uma mulher está presente nessa série infinita, ela é bebê, mãe e avó; ela é mãe, bebê menina e bebê do bebê... É tudo a mesma coisa, porque ela já começa sendo três, enquanto o homem começa com um impulso tremendo para ser um só. Um é um e completamente só, e o será cada vez mais (Winnicott, 2011, p. 193).

Aqui Winnicott elucida o indício metafísico de seu conceito feito de maiúsculas. Ao se referir ao termo MULHER colocando as mulheres numa "série infinita", Winnicott retira o gênero feminino de sua dimensão histórica e, portanto, social e política, reservando tal dimensão aos homens, unos, que precisam buscar se fazer de alguma forma na materialidade do tempo. O status transcendente das mulheres centrado no sexo já as faz ser, desde o início, não deixando espaço para outras identificações que não se deem "de útero para útero". A essencialização da maternidade pelo sexo dá base para a a-historicidade presente no conceito MULHER. Esse aspecto de tomar a mulher pela mãe, no qual se percebe a troca do gênero pelo sexo, pode ser encontrado em outros textos winnicottianos: "É importante levar em conta que uma mãe não só quer filhos, necessita deles.... Ela gosta de ser continuamente importunada pelas necessidades gritantes de seus filhos mesmo que se queixe abertamente de suas obrigações familiares como sendo uma amolação" (Winnicott, 1987, p. 38, grifo nosso).

Dessa forma, entendemos que o conceito MULHER abarca uma tensão entre corpo e cuidado que é apagada pela definição essencializante. Nesse aspecto, a teoria winnicottiana faz impor um corpo específico como início para os cuidados que fundam a subjetividade humana reiterando um discurso social que atrela mulheres e cuidado de crianças. Vale mencionar algumas ideias em que o autor vai na direção contrária da naturalização de mulheres como figuras de cuidado a partir de seus corpos.

Clare Winnicott em sua introdução ao livro Privação e delinquência (Winnicott, 1987) e Adam Phillips (2006) apontam como o período da guerra impactou os estudos winnicottianos. Winnicott assumiu o posto de Psiquiatra Consultor do Plano de Evacuação Governamental numa área de recepção de crianças na Inglaterra. Os autores localizam essa experiência do 
psicanalista como de grande relevância para suas elaborações teóricas durante a guerra e no pós-guerra. Desse modo, Winnicott dedicou muito de seu trabalho para compreender, avaliar e reduzir os impactos da guerra para as famílias que precisavam se separar. Como de costume, o autor se debruça principalmente na relação entre mães e filhos. No texto "A mãe separada do filho", Winnicott (1987) se volta para a difícil situação de uma mãe que teve seu filho evacuado e precisa recebê-lo novamente em seus cuidados:

Haverá um período, por mais breve que seja, após o regresso dos filhos, em que a mãe terá que fingir para as crianças que está disponível para elas, e fingir que necessita delas tanto quanto antes de serem evacuadas; terá que fingir porque, nos primeiros tempos, não se sentirá preparada para isso (Winnicott, 1987, p. 39).

O fingimento da mãe em questão revela algo parecido ao estabelecimento da preocupação materna primária, pois novamente "é preciso tempo para reajustar seu íntimo... para receber os filhos de volta” (Winnicott, 1987, p. 39). Podemos fazer um paralelo com a função da gravidez no despertar da capacidade de adaptação materna, sendo que, no caso dessa reorganização com o retorno da criança evacuada, não há a sensibilização promovida pelas "mudanças fisiológicas" (Winnicott, 1982b, p. 51). Winnicott não explica o que significa esse reajuste do íntimo da mãe, apenas menciona em seguida que ela corre um risco de fracassar em sua tentativa de reajustamento. Parece-nos mais sensato imaginar que para receber uma criança, seja a que retorna, seja pela primeira vez, é preciso uma negociação interna de desejos e identificações. Exatamente por não ser natural, mas sempre um encontro sexual, o encontro com a criança exige trabalho: de amor, de luto, de identificação etc.

$O$ fingimento da mulher que se esforça para ser mãe novamente também vai de encontro à explicação do autor sobre o que é a MULHER. É de se pensar que, se uma mãe tem que fingir para retomar o amor pelos filhos, esse amor não é garantido pela existência de seu útero ou, de modo mais geral, pela sua participação na linhagem a-histórica das mulheres que são sempre e, desde o início, mães (Winnicott, 2011).

Winnicott indica que o medo de ter que realizar um reajuste interno refere-se ao risco de fracassar. Não afirma que o reajuste é muito penoso porque, por exemplo, talvez ela não queira ser mãe, que podem existir conflitos com relação a isso. Mesmo assim, acaba por indicar uma expectativa que não é só de mães e mulheres, mas social, e que incentivos são importantes para que tudo saia como o esperado: que mulheres virem mães, no sentido de serem elas que cuidam de bebês.

O ambiente facilitador não pode ser desconsiderado, ele é repleto de "incentivos sociais". Winnicott sabe e afirma a função dos incentivos: "As mães (ou as mães-substitutas) [mulheres, portanto] geralmente se mostram aptas a atingir esta condição [preocupação materna primária] e pode ser de grande utilidade dizer-lhes que se trata de uma condição passageira, da qual em breve irão se recuperar" (Winnicott, 1996, p. 83).

Nessa direção, os trabalhos winnicottianos direcionados às mães podem ser muito reveladores de tais incentivos, mesmo no que tange aos aspectos teóricos que lhe dão suporte. Em "O bebê como uma organização em marcha”, Winnicott (1982a) afirma: "O bebê foi concebido em você e, a partir desse momento, tornou-se um hóspede em seu corpo. Após o nascimento, ele converteu-se num hóspede em seus braços" (p. 29). O tom descritivo dessa citação carrega, ao mesmo tempo, a suposição/afirmação de uma necessidade. Se o bebê foi concebido no útero materno, ele passa (deve passar) para os braços da mulher-mãe. A responsabilidade pelo cuidado torna-se dela ou, em outras palavras, é incumbida a ela pelo discurso da maternalização.

Percebemos que a discussão dessas ideias traz à tona algumas características conflitantes que se fazem presentes no cuidado e que ficam apagadas na teorização winnicottiana. O exemplo da mãe que precisa fingir seu amor e realizar um reajustamento interno para se haver de fato com as tarefas de cuidado evidencia que é preciso haver trabalho e, por que não, trabalho de recalcamento. $\mathrm{O}$ fingimento traz consigo o desejo de não cuidar, algo que pode se deduzir latente no interior do holding. Quando a criança volta, a mãe tem que fingir que está disponível, "fingir que necessita deles tanto quanto antes de serem evacuadas [em função da guerra]" (Winnicott, 1987, p. 39). A analidade latente no sentido de se evacuar uma criança ajuda na aproximação desse conteúdo latente. Há prazer na retenção e na eliminação. A criança evacuada pode tornar-se indesejável, um alívio mandá-la embora. Seguindo com essa metáfora, 
o trabalho de reajustamento interno que se segue à evacuação refere-se ao recalcamento necessário para a retenção dentro do cuidador da identificação que mantém o cuidado, essa que é muito facilitada/incentivada para as mulheres. Haveria algo assim na paternidade e em outras posições de cuidado? Para que pais assumam as tarefas de cuidado é preciso também que façam tal ajustamento, sustentando dentro de si elementos prazerosos e indesejáveis? Se sim, seriam esses elementos indesejáveis ameaçadores demais para homens de maneira que haja tanta mobilização teórica e social no sentido de atribuir às mulheres os cuidados de bebês?

\section{Gênero, medo e dominação}

Uma vez que o conceito de MULHER é dessencializado a partir da crítica da naturalização do útero que lhe dá fundamento, é possível tomá-lo a serviço da análise sobre os cuidados generificados. Como o autor afirma: "é necessário que exista o termo MULHER, um termo que torna possível a comparação entre homens e mulheres" (Winnicott, 2011, p. 192). Ao concebê-lo como central para compreender as diferenças entre mulheres e homens e, como se procurou demonstrar, possui implicação sobre os cuidados infantis fornecidos por mulheres, cabe investigar também seus impactos sobre os homens e o que pode estar em jogo na sustentação da norma binária de gênero do ponto de vista pulsional.

A saída metafísica apresentada para o conceito de MULHER é realizada por Winnicott (2011) no rascunho da palestra chamada "Este feminismo" cuja data de apresentação é $1964^{3}$. Ao que a pesquisa bibliográfica sugere, essa é uma definição tardia, sendo que sua ideia já se fazia presente em textos bem anteriores através do fenômeno do medo da MULHER, como em "Algumas reflexões sobre o significado da palavra 'democracia'” (Winnicott, 2011), de 1950, em “Preocupação materna primária" (Winnicott, 1982c), de 1956 e em dois trabalhos de 1957, "A contribuição da mãe para a sociedade" (Winnicott, 2011) e "Um homem encara a maternidade" (Winnicott, 1982a). Esse delay sugere que a ideia de MULHER aparece primeiro para Winnicott a partir do fenômeno do medo e, apenas cerca de uma década e meia depois, ele se arrisca a afirmar a definição metafísica do conceito sem mencionar esse afeto. A respeito do medo da MULHER, Winnicott escreve:

É conhecida a raiz desse medo da MULHER. Relaciona-se com o fato de que na história mais remota de todo indivíduo que se desenvolve adequadamente e é são, e que foi capaz de se encontrar a si mesmo, existe um débito para com uma mulher - aquela que se devotou a ele quando ele era bebê, e cuja devoção foi absolutamente essencial para o desenvolvimento saudável desse indivíduo. Essa dependência original não é recordada, exceto quando o medo da MULHER representar o primeiro estágio desse reconhecimento (Winnicott, 2011, pp. 263-264).

Assim, por medo da MULHER Winnicott entende o não reconhecimento da dependência absoluta, a qual, para o autor, é composta necessariamente pelo bebê e por uma mulher que se devota a ele através de cuidados físicos. Segundo Winnicott (2011), essa configuração gera um medo "universal" (p. 263), já que, calcado no fato da dependência, remete aos primeiros momentos da vida de todos, ou seja, quando o bebê e a mãe são uma só unidade (Winnicott, 1996).

De acordo com o autor, para o homem há um impedimento maior, uma vez que ele "não pode fazer o que a mulher faz, esse fundir-se na linhagem, sem violar a essência de sua natureza" (Winnicott, 2011, p. 193). Winnicott se refere como essência da natureza masculina o ser único, o que se sustenta em seu raciocínio pela falta de útero que proporcionaria uma identificação natural. Porém, chama mais a atenção o risco presente de que se possa violar alguma particularidade atribuída a esse gênero. Ao falar sobre o início da formação do eu durante os cuidados da dependência absoluta, Winnicott afirma:

É possível satisfazer um impulso oral e ao fazê-lo violar a função do ego da criança, ou do que será mais tarde zelosamente mantido como o seu self, o núcleo da personalidade. Uma satisfação ali-

\footnotetext{
${ }^{3}$ A ideia presente na definição de MULHER feita em 1964 está presente também em uma nota de rodapé do livro Natureza Humana (conferir Winnicott, 1990, p. 65). Ali o autor afirma que toda mulher é um trio (de três mulheres) durante a relação sexual. Winnicott não desdobra a especificidade do conceito na relação sexual, apenas a menciona. Segundo Claire Winnicott, no prefácio ao livro, o autor começou a escrevê-lo em 1954. Winnicott faleceu 17 anos depois, em 1971. O livro foi publicado postumamente e se encontrava inacabado. Dessa forma, não foi possível afirmarmos em qual período essa definição foi elaborada.
} 
mentar pode ser uma sedução e pode ser traumática se chega à criança sem apoio do funcionamento do ego (Winnicott, 1982b, p. 56, grifos do autor).

A partir de uma perspectiva psicanalítica que privilegia a sexualidade inconsciente, como a de Jean Laplanche (1988), podemos dizer que o amadurecimento descrito por Winnicott (1982b) privilegia demasiadamente os processos de fechamento da constituição subjetiva ao valorizar, por exemplo, termos como continuidade, estabilidade, integração, unidade, dentre outros. Laplanche (1988) denomina de movimento ptolomaico essa progressiva circunscrição do âmbito psíquico a partir da dominância do eu sobre a alteridade que o constitui. O movimento que ressaltamos aqui é, ao contrário, o de apreender o caráter traumático que necessariamente os cuidados infantis carregam. Embora, para Winnicott, a partir do estágio da dependência relativa seja dado um lugar de importância para as violações da onipotência infantil - uma função positiva das falhas ambientais -, o mesmo não ocorre com a dependência absoluta, quer dizer, o autor não toma como fundantes os traumas e seduções que permeiam esse estágio. As violações durante esse período acabam sendo entendidas como problemas de percurso que devem ser evitados por um ambiente suficientemente bom. Mesmo assim, as violações estão presentes: "Há toda a razão para que as mães permitam aos filhos o máximo de contato que eles queiram. Sem dúvida, as sensações dos bebês são, neste aspecto, muito penetrantes e, se são penetrantes, podemos estar certos de que são importantes" (Winnicott, 1982a, pp. 50-51).

Dessa forma, os perigos envolvidos na dependência absoluta reaparecem na vida adulta como medo do poder que a mãe tinha nesse período. Pode-se dizer, medo da mãe que penetra o bebê, algo que aparece em uma das poucas e breves descrições winnicottianas desse fenômeno, como se percebe em uma nota de rodapé:

Podemos entender melhor a idéia [medo de MULHER] se nos aproximarmos dela gradualmente: a) medo dos pais, na infância muito precoce; b) medo da figura combinada: uma mulher que tenha muitos poderes, inclusive potência masculina (a imagem da feiticeira); c) medo da mãe, que teve um poder absoluto no início da existência infantil: o poder de prover ou de fracassar em prover as bases para o estabelecimento inicial do selfindividual (Winnicott, 2011, p. 263).

As agonias primitivas (Winnicott, 1994) que acompanham as falhas ambientais experienciadas pelo bebê winnicottiano no período da dependência absoluta são comumente identificadas pelo autor como o cair para sempre, o retornar ao estado de não integração, o despersonalizar etc. (Winnicott, 1994). Quando descreve o medo de MULHER presente nos adultos, outras palavras identificam tais ansiedades. A começar por "medo", mas também seus complementos como medo da dependência, medo da potência da mãe, medo de seu poder, "incluindo sempre o medo de ser dominado” (Winnicott, 1982a, p. 11).

É importante ressaltarmos que, segundo o autor, o medo da MULHER ou medo da dependência/dominação é um fato universal, mas serve também como forma de diferenciação dos gêneros, como já mencionado. Na construção da maternidade e da paternidade, esse parece ser um diferenciador importante, pois a mãe-mulher pode e deve entrar em contato com a experiência de ser dominada ao readentrar na situação originária a partir do cuidado de bebês e, de uma forma geral, os homens não podem ou não devem participar desse período.

A caracterização winnicottiana das funções paternas ao longo do processo maturacional pode auxiliar na problematização sobre o medo de MULHER e seu impacto na paternidade. Como sintetiza Rosa (2014b), no período da dependência absoluta, o pai não tem uma relação direta com o bebê, uma vez que só há a unidade mãe-bebê, tendo função indireta sobre a criança. Dessa forma, "a qualidade de sua presença [pai] no ambiente... modula o espírito da mãe: o sentimento de estar protegida e amparada depende, em grande parte, do que o pai é capaz de oferecer" (p. 26). Partindo da elaboração da ideia de um medo da MULHER, a proteção fornecida pelo pai à mãe e, indiretamente, ao bebê é também uma autoproteção contra o perigo de ser dominado caso tivesse que assumir para si mesmo a imersão na unidade com o recém-nascido.

A implicação paterna seria impossível na dependência absoluta já que não há como o bebê o reconhecer, mas, como afirma Rosa (2014b), na dependência relativa, isso pode ser feito gradualmente, pois a mãe começa a se desadaptar. A criança já pode estabele- 
cer um "eu sou", ou seja, um eu diferenciado da mãe, e passar a adentrar nas relações triangulares. Nesse momento, o pai passa a ser aos poucos reconhecido como a duplicação de algumas características do cuidado materno. Nas palavras de Winnicott, apreende a existência do pai partir dos seguintes aspectos da mãe: "duro, severo, implacável, intransigente, indestrutível, e que, em circunstâncias favoráveis, vai gradualmente se tornando aquele homem que se transforma num ser humano, alguém que pode ser temido, odiado, amado, respeitado" (Winnicott, 2011, p. 127). A ressonância sexual presente nesses termos faz com que sejam facilmente trocados por ereto, penetrante, impenetrável e inviolável. Dessa forma, cria-se uma figura de homem, seja a do pai ou não, que parece apontar para uma resposta ao desejo/medo da dominação que Winnicott denomina medo de MULHER. O autor está indicando, por um lado, um campo identificatório de dominância e proteção e, por outro, um de dependência, de domínio. Os termos sugerem também fantasias de tipo sadomasoquista presentes no cuidado fornecido por homens, já que a reabertura da cena originária evocaria todas essas defesas dominadoras construídas contra aquela identificação com a dependência do bebê.

Através dessas ideias, podemos dizer que Winnicott sinaliza que a identificação dos bebês e a construção de identidades do gênero passam, antes de chegar ao pai, pela relação de uma dependência radical presente nos cuidados com o bebê. A partir disso, surgem as polaridades ser dominado/dominar, ser violado/ proteger, certamente atrelados a feminino/masculino. O conteúdo sexual que aos poucos vai se entrevendo no medo de MULHER torna-se um dificultador para a aproximação de homens da revivescência da dependência absoluta através da identificação com o bebê por meio do fornecimento de cuidados a eles.

Duas formas de desamparo se aproximam a partir da ideia de medo de MULHER, a do bebê winnicottiano e a dos homens. Do ponto de vista winnicottiano, a dependência radical das origens da vida psíquica alerta para os excessos gerados pelas falhas ambientais presentes nos cuidados físicos e que ultrapassam as capacidades do eu nascente, gerando uma descontinuidade do ser para o bebê. O trabalho do vocabulário e das ideias winnicottianas traz à tona o desamparo do adulto que reexperimenta a cena originária a partir dos cuidados já com suas defesas: há um eu que é atacado por conteúdos sexuais e dos quais suas identificações de gênero tentam lhe proteger.

Winnicott (2011) estabelece uma interessante relação entre o medo de ser dominado e o gosto das pessoas por regimes antidemocráticos e personagens ditadores. O não reconhecimento da dependência faz com que o medo de ser dominado seja também desejo que pode, ao mesmo tempo, ser satisfeito e limitado quando há uma figura de dominação. Dessa forma, ao apontar para as consequências totalitárias do medo da MULHER, afirma que a dominação e a submissão são formas de controlar na fantasia a mulher da infância primitiva. Ao falar do polo dominador, entende que:

se estudarmos a psicologia do ditador, é de esperar que se encontre, entre outras coisas, que em sua luta pessoal está tentando esforçadamente controlar a mulher cujo domínio ele inconscientemente ainda teme, procurando controlá-la servindo-a, atuando para ela e, por seu turno, exigindo total sujeição e "amor" (Winnicott, 1982a, p. 11).

O medo da MULHER entendido como um fenômeno social fornece elementos para sustentar a hipótese de que o desamparo da situação originária a partir da sexualidade adulta presente na dependência radical do bebê retorna como conteúdo atacante ao eu articulando-se a formas defensivas de dominação no âmbito das identificações de gênero. Essa dinâmica parece dar base para a responsabilização teórica e social das mulheres pelos bebês ao distribuir desigualmente, através da dominação de gênero, o desamparo instaurado pela situação de cuidado.

\section{Considerações Finais}

Procuramos analisar a essencialização presente nos argumentos biologicistas de Winnicott que prescrevem, através da psicanálise, uma lógica determinista de gênero para as funções de cuidado de crianças. Considerando que as alterações no corpo da gestante possam facilitar o surgimento de uma grande identificação com o bebê, não por motivos fisiológicos, mas através dos sentidos criados pela expectativa social depositada nessas mudanças corpóreas, não há outros motivos que permitam a naturalização generificada da capacidade de cuidado de bebês e crianças. 
A afirmação de Winnicott (1982a) sobre sua incapacidade de saber sobre o cuidado efetivo com bebês contradiz sua própria atuação clínica em que o psicanalista se mostra bastante capaz de se identificar e oferecer um ambiente suficientemente bom para seus pacientes regredidos à dependência absoluta. $\mathrm{O}$ medo de MULHER parece evocar um desamparo dos homens presente na revivescência da situação originária que é então evitado a partir de uma ordem social de dominação das mulheres.
Buscamos contextualizar e problematizar os posicionamentos teóricos de Winnicott no que concerne à estipulação de uma exclusividade das mulheres no cuidado com crianças e da isenção dos homens dessas tarefas. Neste trabalho apontamos para a necessidade do reconhecimento dos posicionamentos políticos do psicanalista no que diz respeito à dinâmica dos gêneros, além da possibilidade de rearranjos teóricos a partir das pesquisas da área que permitam a potencialização de uma obra tão rica como a de Winnicott.

\section{Referências}

Belo, F. R. R., Guimarães, M. R., \& Fidelis, K. (2015). Pode um pai ser cuidadoso? Crítica à teoria da paternidade em Winnicott. Psicologia em Estudo, 20(2), 153-164. https://doi.org/10.4025/psicolestud.v20i2.24274

Butler, J. (2006). Deshacer el género. Barcelona: Paidós Ibérica.

Butler, J. (2013). Problemas de gênero: Feminismo e subversão da identidade (5a ed., R. Aguiar, Trad.). Rio de Janeiro, RJ: Civilização Brasileira.

Colón, A. R. M. (2009). Maternidad: Significante naturalizado y paradojal: Desde el psicoanálisis hasta el feminismo. Psicologías, 1, 1-10.

Chodorow, N. (1989). Feminism and psychoanalytic theory. New Haven, CT: Yale University.

Doane, J. L., \& Hodges, D. L. (1992). From Klein to Kristeva: Psychoanalytic feminism and the search for the "good enough" mother. Ann Arbor, MI: University of Michigan.

Hjulmand, K. (1999). Lista completa das publicações de D. W. Winnicott. Natureza Humana, 1(2), 459-517.

Horney, K. (1991). Psicologia feminina (T. Rodrigues, Trad.). Rio de Janeiro, RJ: Bertrand Brasil.

Laplanche, J. (1988). Teoria da sedução generalizada e outros ensaios (D. Vasconcellos, Trad.). Porto Alegre, RJ: Artes Médicas.

Laplanche, J. (1992). Novos fundamentos para a psicanálise (C. Berliner, Trad.). São Paulo, SP: Martins Fontes.

Lima, V., \& Belo, F. (2019). Gênero, sexualidade e o sexual: O sujeito entre Butler, Foucault e Laplanche. Psicologia em Estudo, 20(2), 153-164. https://doi.org/10.1590/1807-0329e41962

Mitchel, J. (1979). Psicanálise e feminismo: Freud, Reich, Laing e mulheres (R. Rocha, Trad.). Belo Horizonte, MG: Interlivros.

Phillips, A. (2006). Winnicott (A. Siedschlag, Trad.). São Paulo, SP: Ideias e Letras.

Reeves, C. (2013). On the margin: The role of the father in Winnicott's writings. In J. Abram (Org.), Donald Winnicott today (pp. 358-385). London: Routledge.

Riley, D. (1983). War in the nursery: Theories of the child and mother. London: Virago.

Rosa, C. D. (Org.). (2014a). E o pai? Uma abordagem winnicottiana. São Paulo, SP: DWW.

Rosa, C. D. (2014b). O pai em Winnicott. In C. D. Rosa. (Org.), E o pai? Uma abordagem winnicottiana (pp. 25-62). São Paulo, SP: DWW.

Sayers, J. (1992). Mães da psicanálise: Hélène Deustsch, Karen Horney, Anna Freud, Melanie Klein. Rio de Janeiro, RJ: Zahar.

Scavone, L. (2001). A maternidade e o feminismo: Diálogo com as ciências sociais. Cadernos Pagu, (16), 137-150. https://doi.org/10.1590/S0104-83332001000100008

Stevens, C. M. T. (2005). Ressignificando a maternidade: Psicanálise e literatura. Gênero: Revista do Núcleo Transdisciplinar de Estudos de Gênero, 5(2), 65-79.

Winnicott, D. (1982a). A criança e o seu mundo (6a ed., A. Cabral, Trad.). Rio de Janeiro, RJ: LTC.

Winnicott, D. (1982b). O ambiente e os processos de maturação (I. C. S. Ortiz, Trad.). Porto Alegre, RS: Artes Médicas. 
Winnicott, D. (1982c). Textos selecionados: Da pediatria à psicanálise (2a ed., J. Russo, Trad.). Rio de Janeiro, RJ: Francisco Alves.

Winnicott, D. W. (1987). Privação e delinquência (A. Cabral, Trad.). São Paulo, SP: Martins Fontes.

Winnicott, D. (1990). Natureza humana (D. L. Bogomoletz, Trad.). Rio de Janeiro, RJ: Imago.

Winnicott, D. (1994). Explorações psicanalíticas (J. O. A. Abreu, Trad.). Porto Alegre, RS: Artes Médicas.

Winnicott, D. W. (1996). Os bebês e suas mães (J. L. Camargo, Trad.). São Paulo, SP: Martins Fontes.

Winnicott, D. W. (1999). Conversando com os pais (2a ed., A. Cabral, Trad.). São Paulo, SP: Martins Fontes.

Winnicott, D. W. (2011). Tudo começa em casa (5a ed., P. Sandler, Trad.). São Paulo, SP: Martins Fontes.

\section{Jhonatan Jeison de Miranda}

Mestrando em Psicologia na Universidade Federal de Minas Gerais, Belo Horizonte - MG. Brasil.

E-mail: mirandajjhonatan@gmail.com

(iD) https:// orcid.org/0000-0003-4368-5735

Alberto Luiz Rodrigues Timo

Doutorando em Psicologia Universidade Federal de Minas Gerais, Belo Horizonte - MG. Brasil.

E-mail: albertolrtimo@gmail.com

(iD) https://orcid.org/0000-0002-5643-0208

\section{Fábio Roberto Rodrigues Belo}

Doutor em Estudos Literários pela Universidade Federal de Minas Gerais (UFMG), Belo Horizonte - MG. Brasil. Docente da UFMG.

E-mail: fabiobelo76@gmail.com

(iD https:// orcid.org/0000-0002-5803-1745

Endereço para envio de correspondência:

Universidade Federal de Minas Gerais

FAFICH - Gabinete 4034

Av. Antônio Carlos, 6627. Belo Horizonte - MG - CEP 31270-901

Recebido 10/03/2017

Reformulado 11/03/2019

Aceito 25/06/2019

Received 03/10/2017

Reformulated 03/11/2019

Approved 06/25/2019

Recibido 10/03/2017

Reformulado 11/03/2019

Aceptado 25/06/2019 
Como citar: Miranda, J. J. , Timo, A. L. R. , \& Belo, F. R. R. (2019). Crítica à teoria da maternidade em Winnicott: é preciso ser mulher para cuidar de crianças? Psicologia: Ciência e Profissão, 39, 1-14. https://doi.org/10.1590/1982-3703003176863

How to cite: Miranda, J. J. , Timo, A. L. R. , \& Belo, F. R. R. (2019). A critical approach to Winnicott's theory of motherhood: Do you have to be a woman to take care of children? Psicologia: Ciência e Profissão, 39, 1-14. https://doi.org/10.1590/1982-3703003176863

Cómo citar: Miranda, J. J. , Timo, A. L. R. , \& Belo, F. R. R. (2019). Crítica a la teoría de la maternidad en Winnicott: ¿hay que ser mujer para cuidar de niños? Psicologia: Ciência e Profissão, 39, 1-14. https://doi.org/10.1590/1982-3703003176863 